\title{
Survey of the Opinion of Dentists and Dental Technicians on the Impact of the State of Emergency Related to the Coronavirus Disease 2019 Epidemic in Bulgaria on their Practice
}

\author{
Tanya Bozhkova ${ }^{1 *}$, Nina Musurlieva ${ }^{2}$ \\ ${ }^{1}$ Department of Prosthetic Dentistry, Faculty of Dental Medicine, Medical University - Plovdiv, Plovdiv, Bulgaria; ${ }^{2}$ Department of \\ Social Medicine and Public Health, Faculty of Public Health, Medical University - Plovdiv, Plovdiv, Bulgaria
}

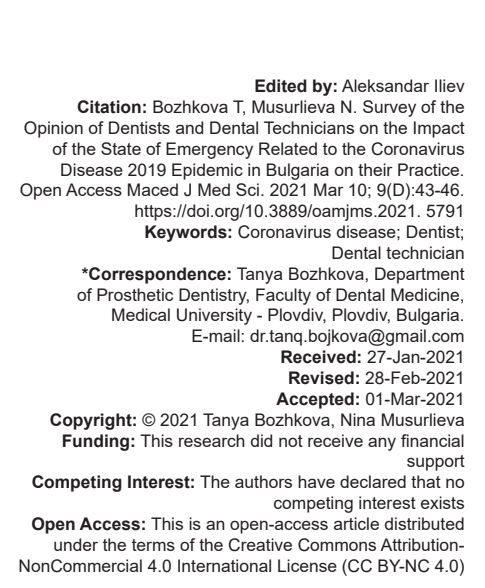

\section{Introduction}

At the end of 2019, the global community was informed about a new human coronavirus severe acute respiratory syndrome coronavirus 2 (SARS-CoV-2), which causes severe acute respiratory syndrome. The infection has an approximate incubation period of 1-14 days, and its clinical symptoms include cough, fever, and shortness of breath [1]. The disease has become a worldwide pandemic, seriously threatening the health of the population and especially that of the medical staff.

In their practice, health-care professionals are at increased risk of coronavirus disease 2019 (COVID-19) infection, which is particularly high for dentists, hygienists, dental assistants, and dental technicians due to close contact with patients and exposure to biological fluids and aerosol/droplets during dental procedures [2], [3].

On the other hand, in the absence of adequate precautions, dental practice could potentially expose patients to the risk of infection, especially the most vulnerable (the elderly, diabetic, and immunocompromised patients) [4]. A state of emergency related to the COVID-19 epidemic was declared in Bulgaria on March 13, 2020. During it, the dentists, following the recommendation of the Crisis Headquarters of the Bulgarian Dental Union, practiced only emergency and urgent dental care to avoid working with dental turbines and scalers, forming aerosol dust.

Dentists who are in close contact with droplets and generated aerosols should review surgical protocols to protect the team and patients from the risk of infectious diseases. The first problem raised with regard to COVID-19 is related to the easy spread of viral agents in the air during dental procedures [1], [2], [3].

The purpose of this study is to survey the opinion of dentists and dental technicians about the impact of the state of emergency in Bulgaria related to the COVID-19 epidemic on their practices.

\section{Materials and Methods}

A specially developed web-based survey conducted among 49 dentists and dental technicians 
was used. The results were processed with SPSS v. 18 at significance level of $p<0.05$.

\section{Results}

A group of 9 dentists and dental technicians were included in the survey. Of them $(20.41 \pm 5.76)$ reported that they did not work at all during the state of emergency.

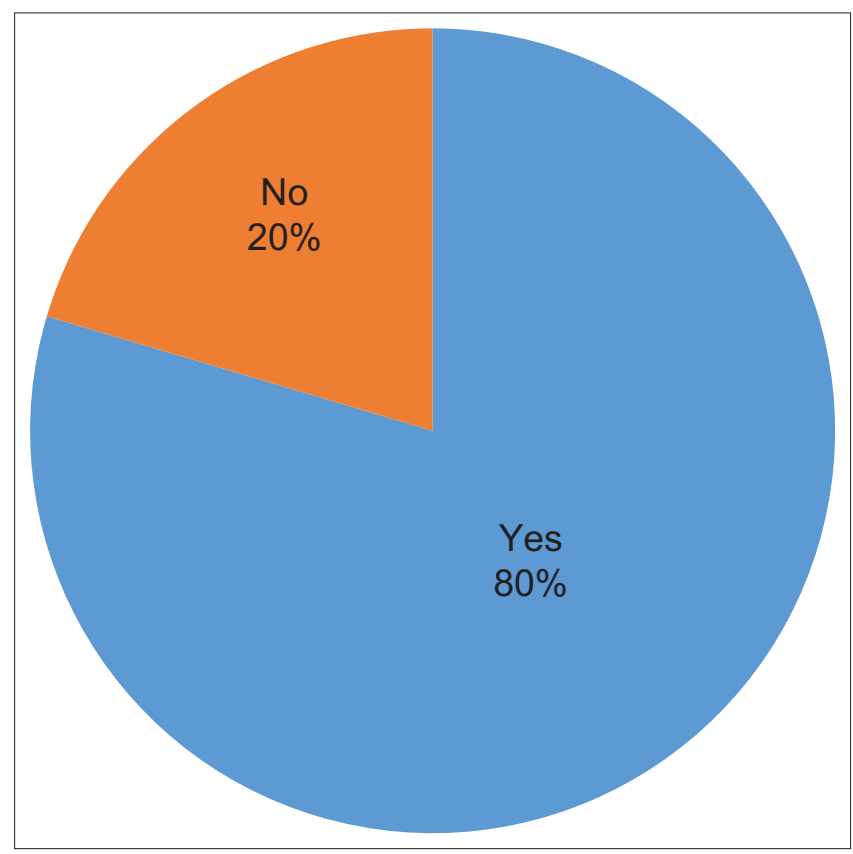

Figure 1: Work of dentists and dental technicians during the period of state of emergency

Relatively, a large number of dentists (81.82 \pm 8.22) respond that they have completely changed their patient care protocols. The result is similar for dental technicians (77.77 \pm 8.00$)$ (Figure 2).

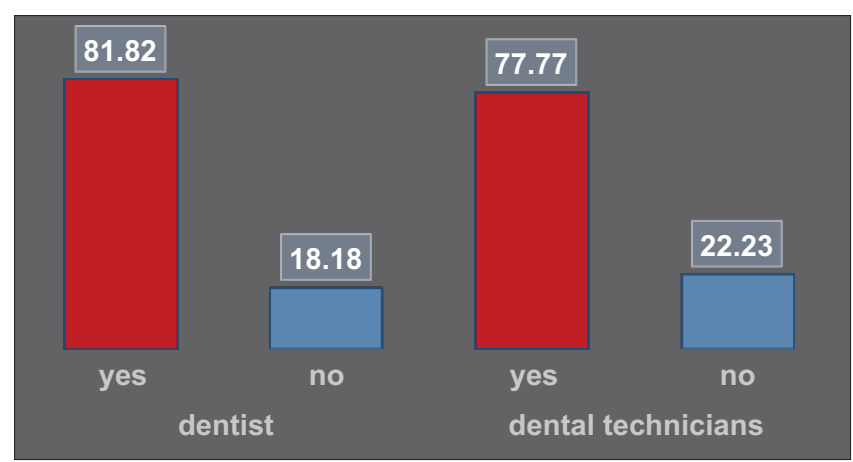

Figure 2: Change patient care protocols

More than half of the dentists $(59.09 \pm 10.48)$ respond that they specifically disinfect the dental impressions, and of the dental technicians (29.63 \pm 8.78) say that they insist on this (Figure 3 ).

All of the respondents share that they use special protective equipment in their practices. The high relative share $(86.36 \pm 7.31)$ of those who encountered difficulties in obtaining them is impressive. The relative share of respondents reporting losses during the period of state of emergency due to the reduced number of patients served is higher. The prices of the offered dental services have not changed, despite the higher price of personal protective equipment and the additional disinfection.

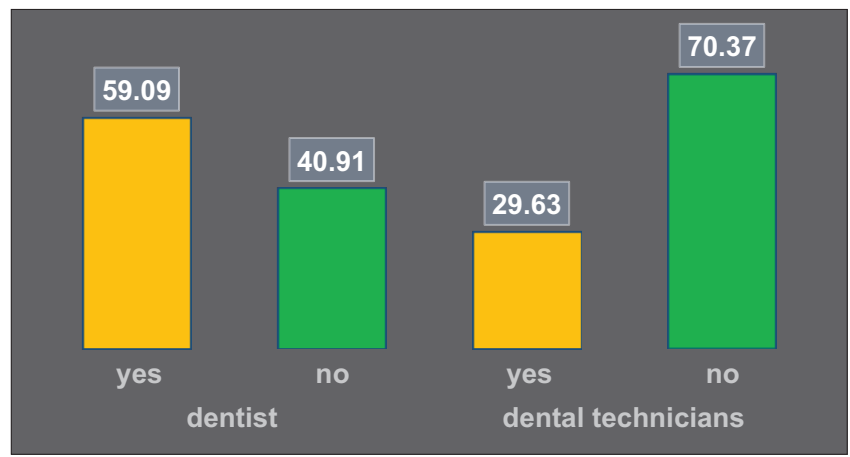

Figure 3: Specifically disinfect the dental impressions

\section{Discussion}

Since its onset in December 2019, COVID-19 has spread rapidly and become a global pandemic. On January 30,2020 , the World Health Organization declared a public health emergency of international concern [5]. Due to the characteristics of dental procedures used for dental treatment, the risk of SARSCoV-2 transmission between dentists and patients is very high [4]. Therefore, all routine dental procedures have been discontinued in many parts of the world, and only emergency care is recommended [6]. The situation is similar in Bulgaria. Of the 49 dentists and dental technicians surveyed, $10(20.41 \pm 5.76)$ report that they did not work at all during the period of state of emergency. The result is logical given that the aerosol is the most aggressive source of COVID-19, which puts dentists and their associates at the forefront of those exposed to the infection and, accordingly, at the forefront of health-care professionals at increased risk of infection [7].

Another problem is related to the persistence of the biological agent in operating rooms. The aerosol produced by high rotation and ultrasonic instruments can remain in the air and on surfaces for several hours [8], [9]. The basic principle of infection control is to approach each patient as if he or she is a potential threat of coronavirus infection and to apply protection and disinfection methods correctly [10]. In this regard, the respondents are asked whether their patient care protocols have changed. Relatively, a large number of dentists $(81.82 \pm 8.22)$ respond positively. The result is similar for dental technicians $(77.77 \pm 8.00)$. It is necessary to conclude that the colleagues follow the recommendations and instructions of the Crisis 
Headquarters of the Bulgarian Dental Union on the rules of aseptic and antiseptic in medical institutions.

There are many invasive treatment techniques in dental practice that distinguishes it from general medical practice. This requires the application of special measures to effectively reduce the risk of transmission of the infection for the safety of dentists, their staff, and patients. There is still little information in the literature about 2019-novel coronavirus (nCoV). Similar genetic characteristics between 2019-nCoV and SARS-CoV indicate that COVID-19 may be sensitive to disinfectants such as $0.1 \%$ sodium hypochlorite, $0.5 \%$ hydrogen peroxide, $62-71 \%$ ethanol, and phenolic and quaternary ammonium compounds [10]. All denture materials, impressions, etc., must be completely disinfected by an intermediate-level disinfectant [11]. Surface disinfection can be performed with $0.1 \%$ sodium hypochlorite or $62-71 \%$ ethanol for $1 \mathrm{~min}$ to eliminate SAS-CoV-2 [12]. Impressions taken with different impression materials after removal from the patient's mouth are rinsed with water and immersed in $5.25 \%$ sodium hypochlorite solution for about $10 \mathrm{~min}$ [12]. Temporary denture structures and partial or total dentures removed from the patient's mouth are immersed in $5.25 \%$ sodium hypochlorite solution for 10 min, and replaceable partial dentures with metal bases are treated with $2 \%$ glutaraldehyde solution and placed in plastic envelope for $10 \mathrm{~min}$ [13]. In the present survey, respondents are asked about the disinfection methods they use. More than half of the respondents $(59.09 \pm 10.48)$ answer that they specifically disinfect the impressions, and the dental technicians (29.63 \pm 8.78) say that they insist on this.

Typical ways of transmission of COVID-19 are sneezing, coughing, inhalation of small particles, and contact transmission, that is, contact with the oral, ocular, and nasal mucosa. Although the typical clinical manifestations of COVID-19 do not include ocular symptoms, examination of conjunctival samples from confirmed and suspected cases of COVID-19 confirmed that COVID-19 transmission is not restricted to the airways and that eye exposure may be potential way for the virus to penetrate. COVID-19 can also be transmitted through saliva directly or indirectly [14], [15], which requires the use of special protective equipment. All of the respondents share that they use special protective equipment in their practices. The high relative share $(86.36 \pm 7.31)$ of those who have encountered difficulties in obtaining them is impressive, because all protective equipment - goggles, helmets, masks, and protective clothing are redirected to hospitals. Dentists fall out of the focus of the state.

In 2020, a survey was conducted by Guo et al. among 2537 dental patients. This survey found that as COVID-19 outbreaks grew, significantly fewer patients visited dental offices. The most common reasons for patient visits are emergencies. Thus, there is evidence to suggest that, following the COVID-19 pandemic, people's demand for dental services may increase dramatically. The situation is similar in Bulgaria. The relative share of the respondents reporting losses during the period of state of emergency is higher due to the reduced number of patients served - 19 (87.00 \pm $7.31)$ by the dentists and $25(92.59 \pm 5.04)$ by the dental technicians.

It is interesting to note that despite the use of additional protective equipment, the prices of dental services have not risen. Only $4(18.18 \pm 8.22)$ of the dentists adjusted their prices, as well as 7 (25.92 \pm 8.43) of the dental technicians.

\section{Conclusion}

Although significant progress has been made in controlling COVID-19 and dental clinics and practices are gradually resuming routine patient care, the prevention and control of SARS-CoV-2 transmission during dental procedures remains a serious challenge. The most critical reason is that asymptomatic patients and patients in their incubation period are also carriers of SARS-CoV-2 and can be a potential threat. All these require special attention by dentists to the application of special protocols for disinfection and sterilization, as well as the wearing of special protective equipment.

It is difficult to identify and quarantine these patients on time, which can lead to SARS-CoV-2 transmission in the population. In addition, close contact between dental staff and patients, as well as droplets and aerosols generated during treatment containing saliva and blood, further increases the risk of SARSCoV-2 transmission in dental practice.

\section{References}

1. Khan S, Ali A, Siddique R, Nabi G. Novel Coronavirus is putting the whole world on alert. J Hosp Infect. 2020;104(3):252-3. https://doi.org/10.1016/j.jhin.2020.01.019

PMid:32032614

2. Izzetti R, Nisi M, Gabriele M, Graziani F. COVID-19 transmission in dental practice: Brief review of preventive measures in Italy. J Dent Res. 2020;99(9):1030-8. https://doi. org/10.1177/0022034520920580

PMid:32302257

3. Peng X, Xu X, Li Y, Cheng L, Zhou X, Ren B. Transmission routes of 2019-nCoV and controls in dental practice. Int J Oral Sci. 2020;12(1):9. https://doi.org/10.1038/s41368-020-0075-9 PMid:32127517

4. Meng L, Hua F, Bian Z. Coronavirus disease 2019 (COVID-19): Emerging and future challenges for dental and oral medicine. J Dent Res. 2020;99(5):481-7. https://doi. 


\section{org/10.1177/0022034520914246}

PMid:32162995

5. World Health Organization Statement on the Second Meeting of the International Health Regulations. Emergency Committee Regarding the Outbreak of Novel Coronavirus (2019-nCoV); 2005. Available from: https://www.who.int/news-room/ detail/30-01-2020-statement-on-the-second-meeting-of-theinternational-health-regulations-(2005)-emergency-committeeregarding-the-outbreak-of-novel-coronavirus-(2019-ncov). [Last accessed on 2020 Jan 30]

https://doi.org/10.4178/epih.e2020013

6. Yang $\mathrm{Y}$, Zhou Y, Liu X, Tan J. Health services provision of 48 public tertiary dental hospitals during the COVID-19 epidemic in China. Clin Oral Investig. 2020;24(5):1861-4. https://doi. org/10.1007/s00784-020-03267-8

PMid:32246280

7. Coulthard P. Dentistry and Coronavirus (COVID-19)-mora decision-making. $\mathrm{Br}$ Dent J. 2020;228(7):503-5. https://doi. org/10.1038/s41415-020-1482-1

PMid:32277203

8. Kampf G, Todt D, Pfaender S, Steinmann E. Persistence of Coronaviruses on inanimate surfaces and their inactivation with biocidal agents. J Hosp Infect. 2020;104(3):246-51. https://doi. org/10.1016/j.jhin.2020.01.022

PMid:32035997

9. Otter JA, Donskey C, Yezli S, Douthwaite S, Goldenberg SD,
Weber DJ. Transmission of SARS and MERS coronaviruses and influenza virus in healthcare settings: The possible role of dry surface contamination. J Hosp Infect. 2016;92(3):235-50. https://doi.org/10.1016/j.jhin.2015.08.027

PMid:26597631

10. Kulekci G, Cintan S, Dulger O. Infection control from the point of dentistry. J Turk Dent Assoc. 2000;58:91-3.

11. Fallahi HR, Keyhan SO, Zandian D, Kim SG, Cheshmi B. Being a front-line dentist during the COVID-19 pandemic: A literature review. Maxillofac Plast Reconstr Surg. 2020;42(1):12. https:// doi.org/10.1186/s40902-020-00256-5 PMid:32341913

12. Fiorillo L, Cervino G, Matarese M, D'Amico C, Surace G, Paduano V, et al. COVID-19 surface persistence: A recent data summary and its importance for medical and dental settings. Int J Environ Res Public Health. 2020;17(9):3132. https://doi. org/10.3390/ijerph17093132 PMid:32365891

13. Upendran A, Geiger Z. Dental Infection Control. Treasure Island, FL, USA: Stat Pearls; 2020.

14. Huang $\mathrm{C}$, Wang $\mathrm{Y}$, Li X, Ren L. Clinical features of patients infected with 2019 novel Coronavirus in Wuhan China. Lancet. 2020;395:497-506.

15. Belser JA, Rota PA, Tumpey TM. Ocular tropism of respiratory viruses. Microbiol Mol Biol Rev. 2013;77(1):144-56.

PMid:23471620 